\title{
PERFILHAMENTO DO CAPIM MULATO II SUBMETIDO A PERÍODOS DE DIFERIMENTO, ADUBAÇÃO NITROGENADA OU ALTURAS INICIAIS
}

\author{
Philipe Lima de Amorim¹, Rafaela Santos Ferreira², Jessica Cintia Ferreira da Silva', Ana Iris Silva dos \\ Santos ${ }^{1}$, Erica Laura Guilherme Lopes ${ }^{1}$, José Teodorico de Araújo Filho ${ }^{1}$, Andressa Mirielle Silva Moreira ${ }^{1}$ \\ ${ }^{1}$ Universidade Federal de Alagoas, Centro de Ciências Agrárias, Rio Largo, Alagoas \\ ${ }^{2}$ Universidade Federal de Sergipe, Departamento de Zootecnia, São Cristóvão, Sergipe \\ *Autor para correspondência: Philipe Lima de Amorim, philipe.amorim@ceca.ufal.br
}

\begin{abstract}
RESUMO: Dois experimentos foram conduzidos, simultaneamente, no período de julho a dezembro de 2017, com o objetivo de estimar os efeitos e interações entre período de diferimento, doses de nitrogênio e altura inicial sobre a dinâmica do perfilhamento de pastos de capim-mulato II. No experimento I foram avaliados os efeitos da combinação de três períodos de diferimento (curto, médio e longo) e doses de nitrogênio ( 0 ou 80 $\mathrm{kg}$ ha-1 de N). No experimento II, foram avaliados os efeitos da combinação dos mesmos três períodos de diferimento do experimento I e duas alturas no início do diferimento (15 ou $30 \mathrm{~cm}$ ). Ambos os experimentos foram conduzidos segundo delineamento inteiramente casualizado em arranjo fatorial $3 \times 2$ com três repetições. No experimento I, houve interação entre os fatores para as variáveis taxa de aparecimento e balanço entre morte e aparecimento de perfilhos, com maiores valores observados nos pastos diferidos por período mais curto e quando receberam adubação nitrogenada. Já para taxa de sobrevivência e índice de estabilidade da população de perfilhos, houve efeito apenas do período de diferimento, com maiores valores observados no período mais curto de diferimento. No experimento II não houve interação para nenhuma das variáveis, sendo observado efeito apenas do período de diferimento. 0 período de diferimento é mais efetivo em alterar as características descritoras do perfilhamento do que a adubação nitrogenada e altura inicial. Período de diferimento mais curto associado a adubação nitrogenada $\left(80 \mathrm{~kg} \mathrm{ha}^{-1}\right)$, independente da altura inicial, alteram positivamente o perfilhamento do capim-mulato II.
\end{abstract}

PALAVRAS-CHAVE: Brachiaria. Pasto diferido. Período seco. Taxa de aparecimento de perfilhos.

\section{TILLERING OF MULATO II GRASS SUBJECTED TO DEFERMENT PERIODS, NITROGEN FERTILIZATION OR INITIAL HEIGHTS}

\begin{abstract}
Two experiments were carried out simultaneously from July to December 2017, in order to estimate effects end interactions between deferment period, nitrogen levels or initial height on the tillering dynamics of mulato II grass. In the experiment I the effects of combination of three deferment periods (short, medium and long) and nitrogen levels ( 0 or $80 \mathrm{~kg} \mathrm{ha}^{-1}$ of $\mathrm{N}$ ) were evaluated. In experiment II, effects of combination of the same three deferment periods of experiment I and two heights at the beginning of deferment (15 or $30 \mathrm{~cm}$ ) were evaluated. Both experiments were conducted in a completely randomized design in a $3 \times 2$ factorial arrangement with three replicates. In experiment I, there was interaction between the factors for rate of appearance and balance between death and tiller appearance, with higher values being observed in the deferred pastures for a shorter period and when they received nitrogen fertilization. For survival rate and stability index of the tiller population, there was effect of deferment period, with higher values being observed in shorter deferment period. In experiment II there was no interaction for any variable. Effect of the deferment period was observed. Deferment period is more effective in altering the descriptive characteristics of the tillering than nitrogen fertilization and initial height. The shorter deferment period associated with nitrogen fertilization, regardless of the initial height, positively alter the tillering of the mulato II grass.
\end{abstract}

KEY-WORDS: Brachiaria. Defered pasture. Dry period. Tiller appearance rate. 


\section{INTRODUÇÃO}

A produção animal em regiões semiáridas é fortemente influenciada pelo regime de chuvas, devido a sua irregularidade e, quando associada à anos de baixa pluviosidade, restringe a oferta de forragem (Furtado et al., 2019). Nesse sentido, dentre as estratégias utilizadas para equilibrar a demanda de forragem durante o período de escassez de forragem, destaca-se o diferimento de pastagens, pela praticidade e menor custo (Santos et al., 2004).

0 diferimento consiste em excluir do pastejo, determinada área da pastagem, no final da estação de crescimento da forrageira, possibilitando, com isso, que se acumule forragem para ser utilizada durante a entressafra (Santos et al., 2009b; Schio et al., 2011). No diferimento de pastagem existem várias ações de manejo, como época, período e altura do pasto no início do diferimento, suplementação e adubação nitrogenada, que devem ser observadas para assegurar bons resultados (Amorim et al., 2017).

Para melhorar a estrutura do pasto diferido e, consequentemente, obter melhor desempenho animal, o pecuarista pode, via manejo do pastejo, modificar ao mesmo tempo a altura inicial ou dose de adubo nitrogenado e a duração do período de diferimento. 0 período de diferimento é uma das ações de manejo de maior efeito sobre as características do pasto diferido e, consequentemente, sobre 0 animal (Fonseca e Santos, 2009). A duração do período de diferimento afeta as características estruturais do pasto, produção e valor nutritivo da forragem (Santos et al., 2009a).

Essas ações de manejo, bem como a interação entre elas, podem modificar 0 ambiente luminoso no interior do dossel e as taxas de crescimento da planta, tendo reflexo na dinâmica da população de perfilhos do pasto. 0 conhecimento da magnitude dessas modificações pode ser utilizado com o objetivo de estimular 0 aparecimento de novos perfilhos vegetativos, garantindo uma população mais jovem, massa de forragem de composição morfológica e valor nutritivo favoráveis ao desempenho animal, sem, no entanto, interferir na perenidade do pasto.

Objetivou-se estimar os efeitos e interações entre período de diferimento, doses de nitrogênio ou altura inicial sobre a dinâmica do perfilhamento de pastos de capim-mulato II.

\section{MATERIAL E MÉTODOS}

Dois experimentos foram conduzidos, simultaneamente, no período de julho a dezembro de 2017, em área de pastagem do setor de Forragicultura da Universidade Federal de Alagoas (UFAL), Centro de Ciências Agrárias, Rio Largo, Alagoas (latitude $9^{\circ} 27^{\prime} \mathrm{S}$, $35^{\circ} 27^{\prime} \mathrm{W}$ longitude e altitude média de $127 \mathrm{~m}$ ).

O clima do município de Rio Largo, de acordo com classificação climática de Köppen é do tipo As, com período seco de setembro a maio. Os dados climáticos ao longo de todo período foram coletados da estação meteorológica do Centro de Ciências Agrárias da Universidade Federal de Alagoas, situada aproximadamente a $300 \mathrm{~m}$ da área experimental.

No experimento I foram avaliados os efeitos da combinação de três períodos de diferimento curto (84 dias), médio (112 dias) e longo (140 dias) e doses de nitrogênio (sem adubação nitrogenada ou com 80 $\mathrm{kg} \mathrm{ha}^{-1}$ de N, sob a forma de ureia, aplicada no início do diferimento). No experimento II, foram avaliados os efeitos da combinação dos mesmos três períodos de diferimento do experimento I e duas alturas no início do diferimento (15 ou $30 \mathrm{~cm}$ ). Ambos os experimentos foram conduzidos em delineamento inteiramente casualizado, em arranjo fatorial $3 \times 2$ (períodos de diferimentos, doses de nitrogênio ou alturas iniciais), com três repetições.

A área experimental consistiu de parte de uma pastagem, já estabelecida, de capim-mulato II, na qual foram alocadas 18 parcelas, para cada experimento, com quatro metros quadrados. Amostras de solo foram colhidas $\mathrm{e}$ analisadas quanto a suas características químicas $\mathrm{e}$ revelaram os seguintes valores: $\mathrm{pH}$ (em água): 6,$4 ; \mathrm{P}=4$ mg. $\mathrm{dm}^{3} ; \mathrm{K}=26 \mathrm{mg}_{\mathrm{dm}} 3 ; \mathrm{Ca}+\mathrm{Mg}=4,3 \mathrm{mmolc}^{2} \mathrm{dm}^{-3} ; \mathrm{H}+\mathrm{Al}$ $=4,5 \mathrm{mmolc} \mathrm{dm}^{-3}$; Capacidade de troca catiônica efetiva $=4,48$; Saturação por bases $=49,8 \%$; saturação por alumínio $=0,4 \%$ e Matéria orgânica $=3,37 \%$.

As parcelas foram diferidas a fim de serem colhidas no início de dezembro do mesmo ano. Sendo assim, as parcelas foram diferidas no final dos meses de julho (140 dias), agosto (112 dias) e setembro (84 dias) de 2017. Na semana em que foi realizado 0 diferimento, no experimento I, os pastos foram manejados e rebaixados de 30 para $20 \mathrm{~cm}$ de altura e mantidos nessa condição até o dia do diferimento, com auxílio de roçadeira costal. No experimento II, os pastos foram mantidos a $30 \mathrm{~cm}$ ou rebaixados a $15 \mathrm{~cm}$ de altura, também com auxílio de roçadeira costal. 
No experimento I, no momento do diferimento, além da adubação nitrogenada (de acordo com 0 tratamento), também foram aplicados, a lanço, $50 \mathrm{~kg}$ ha- 1 de $\mathrm{P}_{2} \mathrm{O}_{5}$ e $\mathrm{K}_{2} \mathrm{O}$ sob a forma de superfosfato simples e cloreto de potássio, respectivamente. No experimento II, no momento do diferimento, independente do tratamento, aplicou-se $70 \mathrm{~kg}$ ha-1 de nitrogênio, sob a forma de ureia, juntamente com o fertilizante fosfatado e potássico, na mesma quantidade e forma utilizadas no experimento I.

Após o diferimento, tiveram início as avaliações dos padrões demográficos de perfilhamento, onde foram selecionadas, aleatoriamente, duas touceiras em cada unidade experimental e identificadas com fios coloridos, para facilitar a avaliação das mesmas. O número de perfilhos inicias foram contados, marcados e a cada 28 dias, até o momento da colheita dos pastos, foram realizadas novas marcações e contagens do número de perfilhos de cada geração existente (cores diferentes).

A partir dos dados colhidos, foram calculadas as taxas de aparecimento (TAP), mortalidade (TMP), balanço entre morte e aparecimento de perfilhos (BAL), sobrevivência (TSP) e índice de estabilidade (IE) da população de perfilhos basilares de acordo com as seguintes fórmulas: Taxa de aparecimento $=\left[n^{0}\right.$ de perfilhos novos (última geração marcada)] $x 100 / n^{0}$ de perfilhos totais existentes (gerações marcados anteriores); Taxa de mortalidade $=$ (perfilhos marcados anteriores - perfilhos sobreviventes) x 100/ $n^{0}$ total de perfilhos na marcação anterior; Balanço entre morte e aparecimento de perfilhos = TAP TMP; Taxa de sobrevivência $=\left(n^{0}\right.$ de perfilhos da marcação anterior vivos na marcação atual x 100)/ $\mathrm{n}^{0}$ de perfilhos vivos na marcação anterior. Índice de estabilidade da população de perfilhos = TSP $(1+$ TAP $)$.

Os dados foram submetidos a análises de variância e as médias comparadas pelo teste de tukey a $10 \%$ de probabilidade para o erro tipo I, com auxílio do software estatístico SISVAR (Ferreira, 2011).

\section{RESULTADOS}

No experimento I, houve interação entre adubação nitrogenada e período de diferimento apenas no período mais curto de diferimento (Figura 1A). Os pastos que receberam adubação nitrogenada, no momento do diferimento, apresentaram TAP superiores aos que não receberam, com valores de 3,18 e 2,13 perfilhos.100perfilhos.dia-1 ${ }^{-1}$, respectivamente. No experimento II (Figura 1B), não houve interação entre altura inicial e períodos de diferimento, havendo, contudo, efeito apenas dos fatores isoladamente (períodos de diferimento). Pastos diferidos por períodos mais curtos apresentaram maiores médias de TAP (2,92 perfilhos.100perfilhos. $\left.\mathrm{dia}^{-1}\right)$ do que os diferidos por períodos mais longos $\left(1,46\right.$ perfilhos.100perfilhos.dia-1 $\left.{ }^{-1}\right)$, sendo que aqueles diferidos por período médio não diferiram dos demais (1,85 perfilhos.100perfilhos. dia $\left.{ }^{-1}\right)$.

Em ambos os experimentos os fatores não interagiram e nem influenciaram a TMP (Figura $2 \mathrm{~A}$ e $2 \mathrm{~B}$ ). No experimento I, houve interação entre adubação nitrogenada e período de diferimento. Apenas no período mais curto adubação influenciou o balanço entre morte e aparecimento de perfilhos (Figura 3A). No período mais curto, os pastos que receberam adubação nitrogenada, no momento do diferimento, apresentaram BAL superiores aos que não receberam, com valores de 2,93 e 1,99 perfilhos.100perfilhos. dia ${ }^{-1}$, respectivamente. No experimento II (Figura 3B), não houve interação entre altura inicial e períodos de diferimento para BAL. No entanto, pastos diferidos por períodos mais curtos apresentaram maiores médias de BAL $(2,67$ perfilhos.100perfilhos. dia $^{-1}$ ) do que os diferidos por períodos mais longos (1,18 perfilhos.100perfilhos. $\left.\mathrm{dia}^{-1}\right)$, sendo que aqueles diferidos por período médio não diferiram dos demais $(1,62$ perfilhos.100perfilhos dia-1).

Não houve interação entre os fatores para TSP, e a mesma foi influenciada pelos períodos de diferimento em ambos os experimentos (Figura 4A e 4B). No experimento I, os pastos diferidos por períodos mais curtos apresentaram maiores TSP (0,99 perfilhos.100perfilhos. dia-1) do que os diferidos por períodos mais longos (0,44 perfilhos.100perfilhos. $\mathrm{dia}^{-1}$ ), sendo os pastos diferidos por tempo médio intermediários $\quad\left(0,8 \quad\right.$ perfilhos.100perfilhos dia $\left.{ }^{-1}\right)$. No experimento II, os pastos que foram diferidos por períodos curtos apresentaram TSP maiores $\left(0,99\right.$ perfilhos.100perfilhos.dia $\left.{ }^{-1}\right)$ que aqueles diferidos por tempo mais longo e médio $(0,44$ e 0,51 perfilhos.100perfilhos. dia-1 ${ }^{-1}$, respectivamente). 
De forma semelhante a TSP, os fatores não interagiram sobre IE em ambos os experimentos, e foi influenciado pelo período de diferimento (Figura $5 \mathrm{~A}$ e $5 \mathrm{~B})$. No experimento I, os pastos diferidos por períodos mais curtos apresentaram maior IE $(3,61)$ do que os diferidos por períodos mais longos $(1,29)$.
No experimento II, os pastos que foram diferidos por períodos curtos apresentaram IE maior $(3,81)$ que aqueles diferidos por tempo mais longo e médio $(1,1$ e 1,67 , respectivamente).

Figura 1. Taxa de aparecimento de perfilhos de pastos de capim-mulato II submetidos a períodos de diferimento,

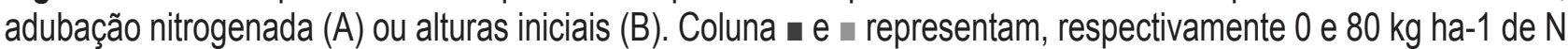
(Figura A).
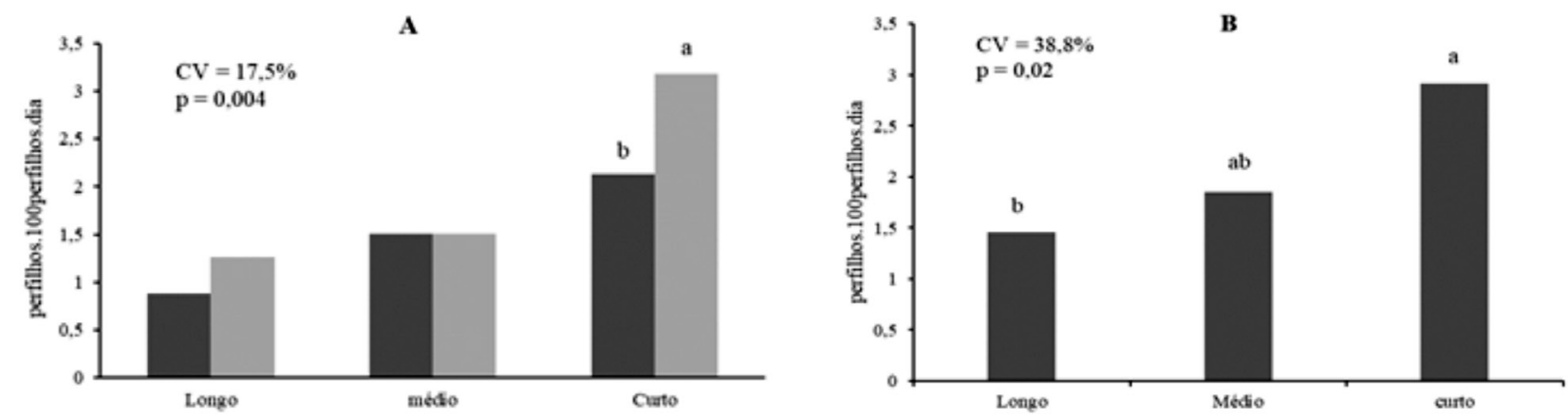

Figura 2. Taxa de mortalidade de perfilhos de pastos de capim-mulato II submetidos a períodos de diferimento, adubação nitrogenada (Figura A) ou alturas iniciais (Figura B). Coluna = e representam 0 e $80 \mathrm{~kg} \mathrm{ha}^{-1}$ de N (Figura A) ou 15 e $30 \mathrm{~cm}$ de altura (Figura B), respectivamente.
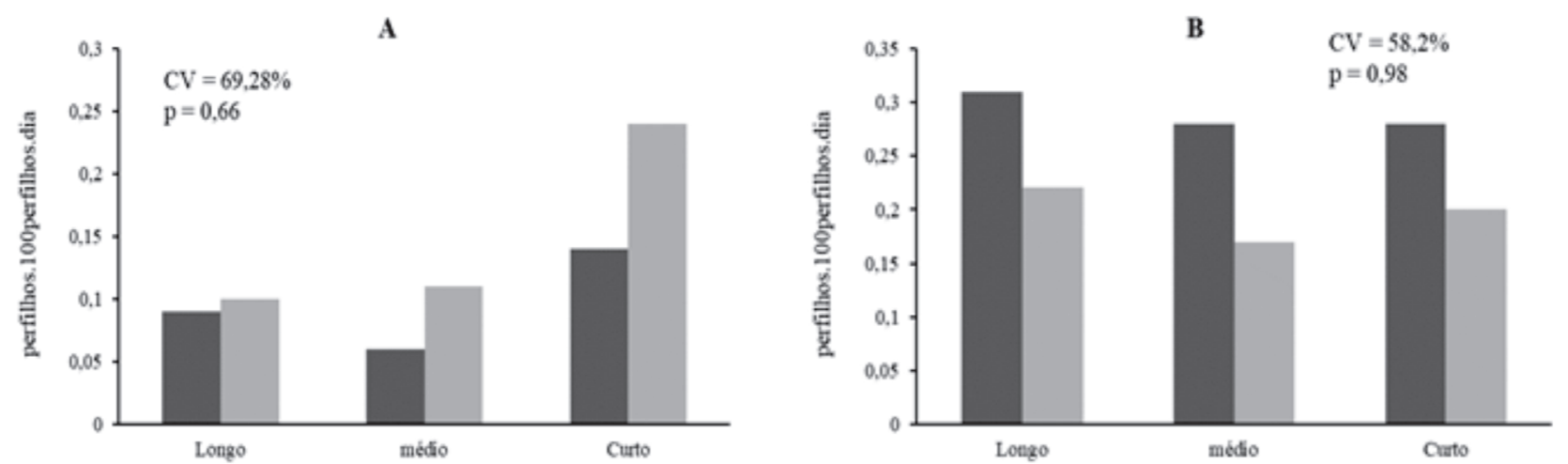

Figura 3. Balanço entre morte e aparecimento de perfilhos de pastos de capim-mulato II submetidos a períodos de diferimento, adubação nitrogenada (A) ou alturas iniciais (B). Coluna $\mathbf{e} \approx$ representam, respectivamente $0 \mathrm{e}$ $80 \mathrm{~kg} \mathrm{ha}^{-1}$ de N (Figura A).
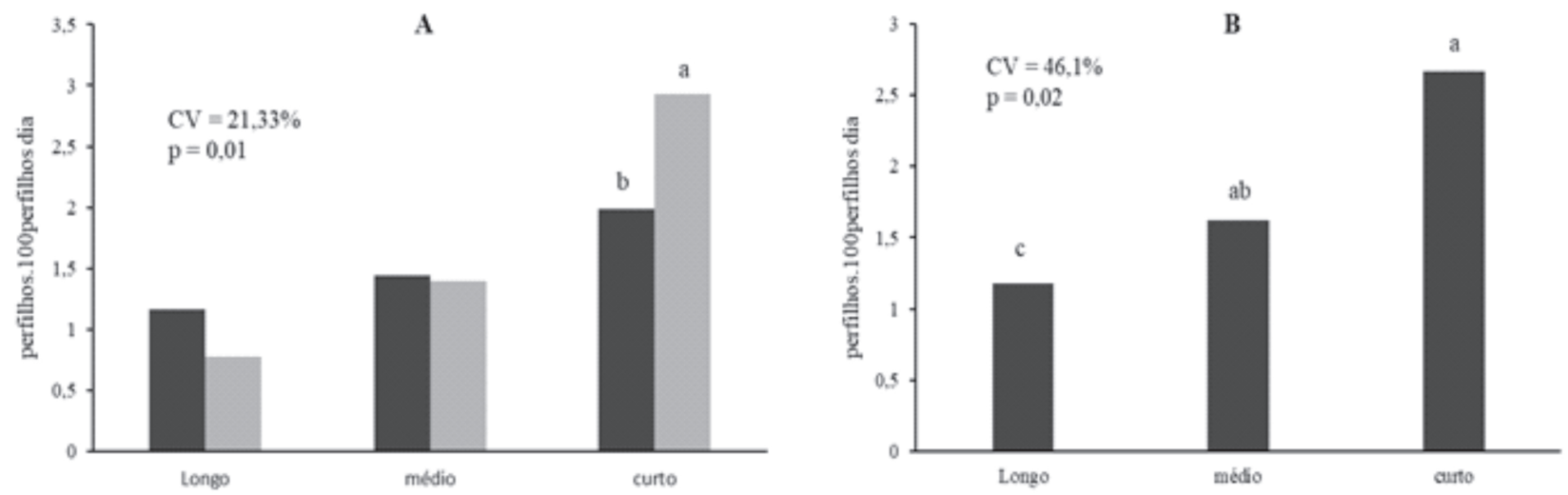
Figura 4. Taxa de sobrevivência de perfilhos de pastos de capim-mulato II submetidos a períodos de diferimento, adubação nitrogenada ou alturas iniciais.
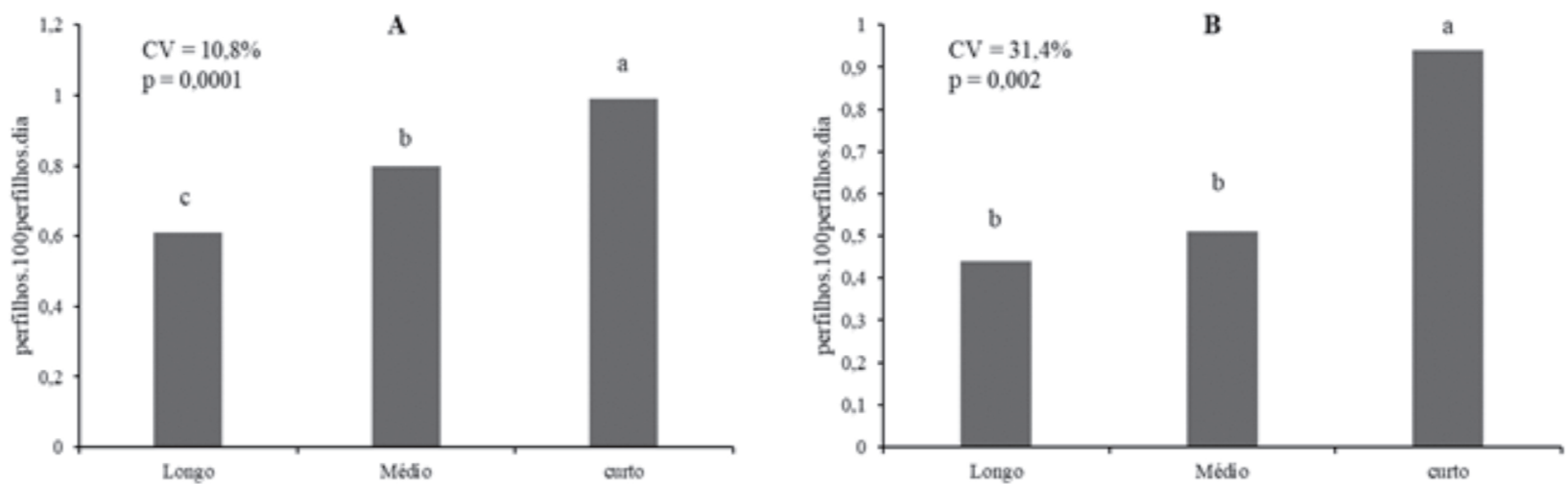

Figura 5. Índice de estabilidade da população de perfilhos de pastos de capim-mulato Il submetidos a períodos de diferimento, adubação nitrogenada ou alturas iniciais.

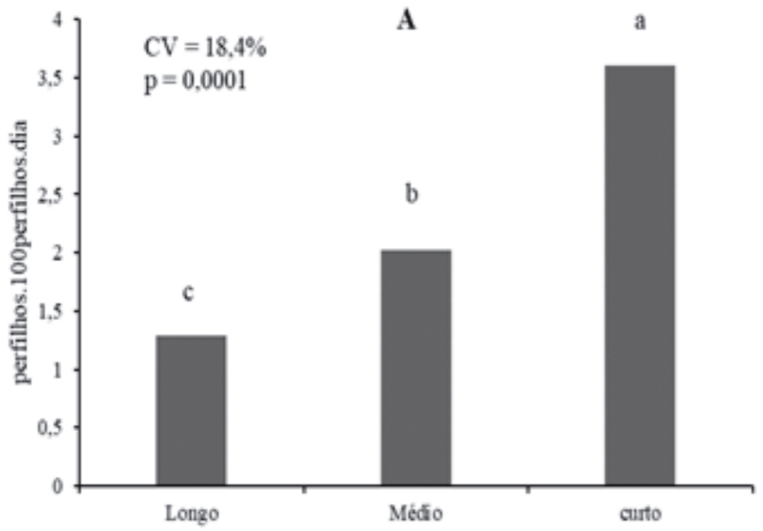

\section{DISCUSSÃO}

O período de diferimento é uma das ações de manejo que possui a capacidade de modificar, de forma significante, a características estruturais do pasto. Quando o pasto é submetido a períodos de diferimento mais longos é comum observar aumento da altura do dossel e, consequentemente, do índice de área foliar (Santos et al., 2009a; Vilela et al., 2012). $O$ aumento do IAF causa modificações no ambiente luminoso dentro do dossel, iniciando pela diminuição da penetração da luz, bem como sobre a qualidade da luz, o que contribui para diminuição do aparecimento de novos perfilhos (Deregibus et al., 1983).

$O$ efeito da modificação do ambiente luminoso sobre a TAP pode ser observado nas figuras $1 \mathrm{~A} e$ 1B. Em ambos os experimentos a TAP foi reduzida, significativamente, quando o pasto foi diferido por períodos mais longos, quando comparado aos diferidos por períodos mais curtos. Os efeitos negativos de pastos diferidos por períodos mais longos diminuíram também 0 efeito da adubação nitrogenada e altura

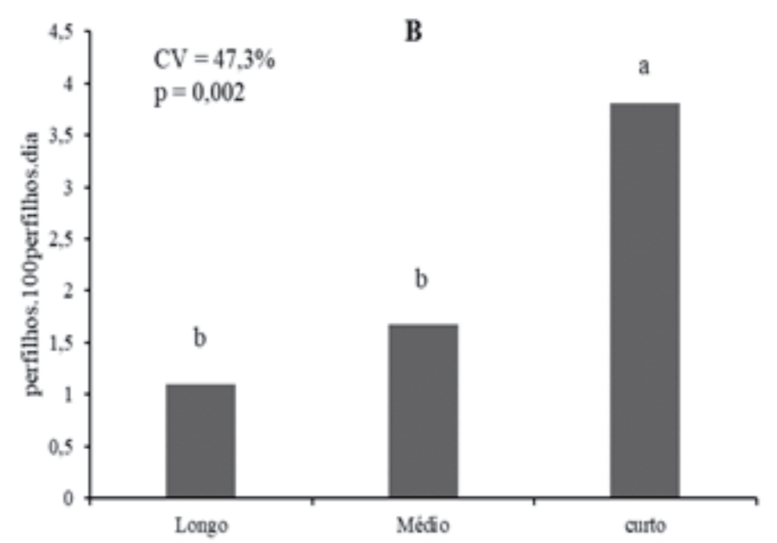

inicial, ações de manejo estas que, quando utilizadas corretamente, influenciam positivamente a estrutura do pasto (Santos et al., 2013; Sousa et al., 2012). No caso do experimento I a adubação nitrogenada, que tem efeito positivo e reconhecido sobre o perfilhamento de gramíneas (Fagundes et al., 2006; Morais et al., 2006), teve influência apenas nos pastos diferidos por períodos curtos. Nesse caso, além do ambiente luminoso favorável na base do dossel (pastos mais baixos), nesse período observou-se também maior irradiação solar, chuvas e altas temperaturas (Tabela 1), o que contribuiu para o incremento do efeito da adubação nitrogenada. É provável que no início da rebrotação dos pastos diferidos por período mais longos, 0 efeito do nitrogênio sobre a TAP pode ter ocorrido, no entanto, com o avançar da rebrotação e aumento excessivo do IAF, esse efeito pode ter sido reduzido. Souza et al., (2013) observaram, que nos primeiros 30 dias de diferimento, a TAP era elevada, reduzindo-se ao longo do período, ao ponto dos efeitos das alturas iniciais não fossem mais observadas ao final do diferimento. 
Tabela 1. Resultado mensal das variáveis meteorológicas durante o período experimental

\begin{tabular}{lcccccc}
\hline \multirow{2}{*}{ Mês } & \multicolumn{7}{c}{ Variáveis } \\
\cline { 2 - 6 } & Tméd & Tmáx & Tmín & Irradiação & Umidade & Precipitação \\
\hline Julho & 22,0 & 27,1 & 17,0 & 12,8 & 84,6 & 418,1 \\
Agosto & 22,5 & 29,1 & 18,1 & 16,7 & 83,3 & 154,9 \\
Setembro & 22,8 & 28,3 & 17,6 & 19,6 & 80,6 & 120,1 \\
Outubro & 24,0 & 30,1 & 18,9 & 21,1 & 78,2 & 37,1 \\
Novembro & 25,0 & 32,9 & 19,2 & 23,3 & 74,7 & 14,2 \\
Dezembro & 25,8 & 34,5 & 20,1 & 22,4 & 74,2 & 69,3 \\
\hline Média & 23,7 & 30,3 & 18,5 & 19,3 & 79,3 & $813,7^{*}$ \\
\hline Tméd $\left({ }^{\circ} \mathrm{C}\right):$ temperatura média; Tmáx: temperatura máxima; Tmín: temperatura mínima; Irradiação solar global $\left(\mathrm{MJ} \mathrm{m}^{-2}\right.$ dia $\left.^{-1}\right) ;$ Umidade do ar $(\%)^{*}$ \\
Precipitação Pluvial (mm); ${ }^{*}$ acumulado.
\end{tabular}

A ausência de efeitos das ações de manejo sobre a TMP pode ser atribuída pelo diferimento ter sido realizado em períodos distintos (Souza et al., 2013). Os autores ainda observaram que pastos diferidos ainda com condições climáticas favoráveis a TMP era proveniente da remoção dos meristemas apicais dos perfilhos durante o corte, já pastos diferidos no final do período chuvoso, a mortalidade foi atribuída, além da intensa elevação do IAF e interceptação luminosa, as condições climáticas que já estavam se tornando desfavoráveis.

O perfilho é a unidade modular de crescimento das gramíneas forrageiras (Hodgson, 1990). O perfilhamento nas gramíneas forrageiras contribui para a adaptação às distintas condições de ambiente, incluindo as estratégias de manejo, o que confere à planta a plasticidade fenotípica (Santos et al., 2009d). Ainda segundo os autores, as estratégias de manejo, além de garantirem o equilíbrio entre a demanda de forragem e sua oferta aos animais, devem manter a sustentabilidade da pastagem. Nesse estudo os valores positivos do balanço entre morte e aparecimento de perfilhos indicam que as estratégias de manejo testadas, em ambos os experimentos, não foram capazes de comprometer a perenidade do capim-mulato II. Em ambos os experimentos, embora não tenha sido observado valores negativos de BAL, de maneira geral, nos pastos que foram diferidos por períodos mais longos foi onde observou-se os menores valores. No caso do experimento I, onde houve interação entre o período de diferimento e adubação nitrogenada, esse padrão de resposta pode ser atribuído ao efeito, já reconhecido, do nitrogênio sobre a TAP em detrimento da TMP.

Embora a TMP não tenha sofrido efeito das ações de manejo para diferimento, em ambos os experimentos, a TSP diminuiu quando os pastos foram diferidos por períodos mais longos. Em pastos diferidos por períodos mais longos, a menor TSP pode ser proveniente da mudança de estádio fenológico dos perfilhos durante o período de diferimento, que entraram em estádio reprodutivo e posteriormente morreram. Adicionalmente, é possível que perfilhos vegetativos de menor tamanho tenham sido sombreados e, com isso, morreram em razão da competição por luz com os perfilhos mais velhos e de maior tamanho. Quando em situação de sombreamento, infere-se que maior quantidade de assimilados é alocada para o crescimento de perfilhos já existentes em detrimento do desenvolvimento de novos perfilhos (Santos et al., 2010b).

A análise conjunta das variações na TAP e TMP podem ser melhor observadas pelo índice de estabilidade de perfilhos (Bahmani etal., 2003). No geral, valores menores que 1,0 indicam que a sobrevivência e aparecimento de novos perfilhos não são suficientes para compensar as taxas de mortalidade e, portanto, a densidade tende a diminuir. Valores superiores a 1,0 sugerem uma situação inversa. Valores próximos de 1,0 indicam uma densidade estável, em que o número de perfilhos praticamente não varia, apesar de ser resultado de um equilíbrio dinâmico (Bahmani et al., 2003). Nos dois experimentos, pastos diferidos por períodos mais longos apresentaram menores valores de IE do que aqueles diferidos por períodos mais curtos. No entanto, em nenhum dos experimentos esses valores ficaram abaixo de 1,0, indicando que as ações de manejo avaliadas não induzem a diminuição da população de perfilhos e, consequentemente, a degradação dos pastos.

0 período de diferimento é mais efetivo em alterar as características descritoras do perfilhamento 
do que a adubação nitrogenada e altura inicial. Período de diferimento mais curto associado à adubação nitrogenada, independente da altura inicial, alteram positivamente o perfilhamento do capim-mulato II.

\section{REFERÊNCIAS BIBLIOGRÁFICAS}

Amorim, P. L.; Fonseca, D. M.; Santos, M. E. R.; Pimentel, R. M.; Rodrigues, J. P. P.; Vitor, C. G. Rebrotação na primavera e desempenho de bovinos em pastos de capim-braquiária adubados com nitrogênio antes do diferimento. Revista Ciência Agrícola, 2017, $15,2,29-35$.

Bahmani, I.; Thom, E. R.; Matthew, C.; Hooper, R. J.; Lemaire, G. Tiller dynamics of perennial ryegrass cultivars derived from different New Zealand ecotypes: effects of cultivars, season, nitrogen fertilizer, and irrigation. Australian Journal of Agricultural Research, 2003, 54, 8, 803-817.

Deregibus, V. A.; Sanchez R. A.; Casal, J. J. Effects of light quality on tiller production in Lolium spp. Plant Physiology, 1983, 72, 900-912.

Fagundes, J. L; Fonseca, D. M.; Morais, R. V.; Vitor, C. M. T.; Gomide, J. A.; Nascimento Júnior, D.; Santos, M. E. R.; Lambertucci, D. M. Avaliação das características estruturais do capim-braquiária em pastagens adubadas com nitrogênio nas quatro estações do ano. Revista Brasileira de Zootecnia, 2006, 35, 1, 30-37.

Ferreira, D. F. Sisvar: a computer statistical analysis system. Ciência e Agrotecnologia, 2011, 35, 6, 10391042.

Fonseca, D. M.; Santos, M. E. R. Diferimento de pastagens: estratégias e ações de manejo. In: Souza, F. F.; Evangelista, A. R.; Lopes, J.; Faria, D. J. G.; Vinente, A. K.; Fortes, C. A.; Babilônia, J. L. (Org.). Simpósio, 7.; Congresso de Forragicultura e pastagens, 3., 2009, Lavras, MG. Anais... Lavras, MG, 2009. p. 65-88.

Furtado, R. N.; Carneiro, M. S. S.; Coutinho, D. N.; Cândido, M. J. D.; Silva, E. B. Fermentative losses and chemical composition of elephant grass silage added with castor bean hull. Revista Ciência Agronômica, 2019, 50, 1, 140-147.
Hodgson, J. Grazing management: science into practice. Essex: Longman Scientific \& Technical, 1990. 203p.

Morais, R. V.; Fonseca, D. M.; Nascimento Júnior, D.; Ribeiro Júnior, J. I.; Fagundes, J. L.; Moreira, L. M.; Mistura, C.; Martuscello, J. A. Demografia de perfilhos basilares em pastagem de Brachiaria decumbens adubada com nitrogênio. Revista Brasileira de Zootecnia, 2006, 35, 2, 380-388.

Santos, E. D. G.; Paulino, M. F.; Queiros, D. S.; Fonseca, D. M.; Valadares Filho, S. C.; Lana, R. P. Avaliação de pastagem diferida de Brachiaria decumbens Stapf. 2. Disponibilidade de forragem e desempenho animal durante a seca. Revista Brasileira de Zootecnia, 2004, $33,1,214-224$.

Santos, M. E. R.; Fonseca, D. M.; Balbino, E. M.; Monnerat, J. P. I.; Silva, S. P. Capim-braquiária diferido e adubado com nitrogênio: produção e características da forragem. Revista Brasileira de Zootecnia, 2009a, $38,4,650-656$.

Santos, M. E. R.; Fonseca, D. M.; Euclides, V. P. B.; Nascimento Júnior, D. Queiroz, A. C.; Ribeiro Júnior, J. I. Características estruturais e índice de tombamento de Brachiaria decumbens cv. Basilisk em pastagens diferidas. Revista Brasileira de Zootecnia, 2009b, 38, 4, 626-634.

Santos, M. E. R.; Fonseca, D. M.; Euclides, V. P. B.; Ribeiro Júnior, J. I.; Nascimento Júnior, D.; Moreira, L. M. Produção de bovinos em pastagens de capimbraquiária diferidas. Revista Brasileira de Zootecnia, 2009c, 38, 4, 635-642.

Santos, M. E. R.; Fonseca, D. M.; Balbino, E. M.; Monnerat, J. P. I.; Silva, S. P. Caracterização dos perfilhos em pastos de capim-braquiária diferidos e adubados com nitrogênio. Revista Brasileira de Zootecnia, 2009d, 38, 4, 643-649.

Santos, M. E. R.; Fonseca, D. M.; Gomes, V. M.; Balbino, E. M.; Magalhães, M. A. Estrutura do capim-braquiária durante o diferimento da pastagem. Acta Scientiarum. Animal Sciences, 2010b, 32, 2, 139-145. 
Santos, M. E. R.; Silveira, M. C. T.; Gomes, V. M.; Fonseca, D. M.; Sousa, B. M. L.; Santos, A. D. Pasture height at the beginning of deferment as a determinant of signal grass structure and potential selectivity by cattle. Acta Scientiarum. Animal Sciences, 2013, 35, 4, 379-385.

Schio, A. R.; Veloso, C. M.; Silva, F. F.; Ítavo, L. C. V.; Mateus, R. G.; Silva, R. R. Ofertas de forragem para novilhas nelore suplementadas no período de seca e transição secaláguas. Acta Scientiarum Animal Sciences, 2011, 33, 1, 9-17.

Souza, B. M. L.; Santos, M. E. R.; Vilela, H. H.; Silveira, M. C. T.; Rocha, G. O.; Freitas, C. A. S.; Silva, N. A. M.; Nascimento Júnior, D. Piata palisade grass deferred with two distinct initial heights: luminous environment and tillering dynamics. Revista Brasileira de Zootecnia, 2013, 42, 36-43.
Souza, B. M. L.; Vilela, H. H.; Santos, A. L.; Santos, M. E. R.; Nascimento Júnior, D.; Assis, C. Z.; Faria, B. D.; Rocha, G. O. Piata palisadegrass deferred in the fall: effects of initial height and nitrogen in the sward structure. Revista Brasileira de Zootecnia, 2012, 41, 5, 1134-1139.

Vilela, H. H.; Sousa, B. M. L.; Santos, M. E. R.; Santos, A. L.; Assis, C. Z.; Rocha, G. O.; Faria, B. D.; Nascimento Júnior, D. Forage mass and structure of piatã grass deferred at different heights and variable periods. Revista Brasileira de Zootecnia, 2012, 41, 7, 1625-1631. 